\title{
Different free-running periods in split components of the circatidal rhythm in the shore crab Carcinus maenas
}

\author{
D. G. Reid*, E. Naylor \\ School of Ocean Sciences, University College of North Wales, Bangor, Gwynedd LL57 2UW, United Kingdom
}

\begin{abstract}
Bimodal circatidal rhythms were induced in freshly caught specimens of the shore crab Carcinus maenas (L.) by introduction into dilute seawater at the time of 'expected' low water. In subsequent constant conditions, some individuals displayed 2 peaks in each tidal wavelength which were phased to either 'expected' high water or at approximately $12.5 \mathrm{~h}$ intervals after introduction. In a number of these crabs, the 2 series of peaks exhibited significantly different periods. These findings confirm the proposition that $C$. maenas has at least 2 functionally independent circatidal oscillators. These oscillators are differentiated by entraining influence, not by function, in contrast to multiple circadian rhythms.
\end{abstract}

KEY WORDS: Carcinus maenas · Circatidal rhythms · Clock splitting

\section{INTRODUCTION}

The control of circadian rhythmicity by multiple oscillators is well documented. The different oscillators or groups of oscillators are believed to act separately to control different aspects of an animal's behaviour or physiology. One of the most widely studied examples is the rhythmic behaviour of the golden hamster Mesocricetus auratus in which different oscillators have been suggested for the control of dawn and dusk activity peaks (Pittendrigh \& Daan 1976, Turek et al. 1982), activity onset and offset (Mrosovsky \& Hallonquist 1986) and for drinking and running activity (Shibuya et al. 1980).

The possibility of more than 1 circatidal oscillator controlling circatidal rhythms has attracted less attention. Palmer \& Williams (1986a) proposed a system of 2 circalunadian (lunar day) clocks, loosely coupled in antiphase, for the control of circatidal rhythms in the crab Helice crassa. However, such a model could be

\footnotetext{
- Present address: Scottish Office Agriculture and Fisheries Department, Marine Laboratory, Victoria Road, PO Box 101, Torry, Aberdeen, UK
}

envisaged as a pair of circadian oscillators in antiphase, a similar model to that proposed for the dawn/dusk activity pattern of Mesocricetus sp. (see above). There are reports of artificially entrained, freerunning bimodal circatidal rhythms in intertidal species where such rhythms would not normally be expected, for example Corophium volutator (Harris \& Morgan 1984), Eurydice pulchra (D. G. Reid unpubl.) and Carcinus maenas (Bolt et al. 1989). A bimodal circatidal rhythm is considered as having 2 peaks of activity in every 1 tidal cycle. One possible explanation of such rhythms is that they arise as a result of a circatidal clock being 'split' into 2 separate components which subsequently become coupled in antiphase. The theoretical basis of such antiphase coupling of split circadian components has been established by Daan \& Berde (1978).

In a separate paper we have investigated the potential for clock splitting in one of the above intertidal species, the shore crab Carcinus maenas (Reid \& Naylor 1990). Circatidal rhythmicity in C. maenas can be artificially entrained by tidal cycles of 3 environmental variables: salinity, temperature and hydrostatic pressure (Naylor \& Williams 1984). Bimodal circatidal 
rhythms can be entrained by exposure of arhythmic crabs to cycles of any 2 of these zeitgebers applied in tidal antiphase. Bimodal rhythms can also be entrained by exposing freshly captured rhythmic crabs to cycles of any one of these variables applied in antiphase to the 'expected' regime on the shore where the crabs were captured. In a number of cases the bimodal rhythms subsequently persisted in constant conditions. As this apparent clock-splitting could be induced by cycles of any 2 of the 3 zeitgebers applied in antiphase, we concluded that the most likely explanation is that circatidal rhythmicity in this species is controlled by at least 2 oscillators or oscillator components (Reid \& Naylor 1990). These oscillators may either have differential sensitivity to the different zeitgebers or may be specific to an individual zeitgeber. Under some circumstances these different components could be entrained with different phases, and may thus appear as a 'bimodal' circatidal rhythm.

The aim of the present investigation was to examine the 'split' components of circatidal rhythmicity in Carcinus maenas more closely. It is not clear from the work to date whether these components could be considered as separate oscillators, as is the case with the separate components of circadian rhythmicity in Mesocricetus sp. (Pittendrigh \& Daan 1976, Turek et al. 1982, Lees et al. 1983, Mrosovsky \& Hallonquist 1986) or whether they are both controlled by a single oscillator. If there were 2 oscillators controlling the 2 split components it would be expected that they would, occasionally, free-run with different periods, as was observed with the multiple circalunadian oscillators controlling circatidal rhythmicity in Helice sp. (Palmer \& Williams 1986a). Secondly, if separate oscillators were involved, one would expect to be able to entrain bimodal rhythmicity with zeitgeber cycles applied asymmetrically within the tidal period. For this investigation we examined the characteristics of free-running bimodal circatidal rhythms in C. maenas induced by hypo-osmotic shock. In previous work we have shown that the sudden transfer to dilute seawater, from full seawater, will start up circatidal rhythmicity in previously arhythmic crabs (Reid \& Naylor 1989). In the present study we have used hypo-osmotic shock as a convenient method of starting up free-running bimodal circatidal rhythms in freshly captured crabs which would normally only display unimodal circatidal rhythms of locomotor activity.

\section{MATERIAL AND METHODS}

Carcinus maenas (L.) were freshly collected for each experiment from the intertidal zone of the Menai Strait, North Wales using baited traps, from April to
September. Male crabs of between 45 and $60 \mathrm{~mm}$ carapace width were transferred to the laboratory and used immediately for the experiments. Locomotor activity was monitored in a wheel actograph system connected to a BBC ' $\mathrm{B}$ ' microcomputer as described in Bolt \& Naylor (1986). Each crab was enclosed in a cylindrical cage approximately $6 \mathrm{~cm}$ high by $30 \mathrm{~cm}$ diameter, in most respects very similar to the hamster running wheels used in many investigations of circadian rhythms. Small magnets were attached at $90^{\circ}$ intervals around the rim of the wheel. The cages were suspended vertically in individual tanks provided with a sufficient depth of $20 \%$ seawater ( 7 ppt salinity) to cover the crab when it was at the bottom of the cage. Any movement by the crabs caused the wheels to rotate and this was detected by a reed switch fastened to the outside of the tank and connected to the microcomputer. Each activation of a reed switch by a magnet was recorded on the microcomputer as an event.

In the main series of trials 200 crabs were placed into $20 \%$ seawater in the actographs approximately $6 \mathrm{~h}$ after high water and their subsequent activity monitored in constant darkness at $15^{\circ} \mathrm{C}$. Crabs remained unfed for the duration of each experiment. Two further sets of experiments were also carried out. In the first, 30 crabs were placed into actographs containing $100 \%$ seawater $(34 \mathrm{ppt})$, to test whether the capture and transfer into the actographs alone induced any subsequent changes in activity pattern. In the second set of experiments 24 crabs were placed into dilute seawater $3 \mathrm{~h}$ after expected high water. This was to establish whether bimodal circatidal rhythmicity could be induced with different phase relationships between the 2 series of peaks, i.e. other than with a $180^{\circ}$ antiphase relationship to the time of 'expected' high water. In all the experiments the crabs were used only once and then returned to the sea.

Spontaneous locomotor activity patterns are plotted in a series of consecutive $12.5 \mathrm{~h}$ (tidal) periods. Locomotor activity is plotted as a percentage of the maximum activity in any 1 interval (15 or $30 \mathrm{~min}$ ) against the elapsed time.

To allow comparison of the free-running patterns of the natural and the induced components of bimodal circatidal rhythms of locomotor activity, events recorded from the actographs were summed every 15 or $30 \mathrm{~min}$, and for every $12 \mathrm{~h}$ period the mean of all 15 or 30 min activity values was calculated. Peaks of activity were characterised as occurring when at least 2 consecutive 15 or 30 min periods occurred in which the activity level rose above the mean. The time of each peak was then defined and recorded as an average of 2 measures: the median time of the peak and the time of greatest activity. Results were plotted as the calculated time of each peak against elapsed 
number of tidal cycles for each of 2 hypothesised split oscillator components; one induced by the hypoosmotic shock, the other phased to the time of expected high water.

The results are plotted in $12 \mathrm{~h}$ segments against the elapsed number of 'expected' tidal cycles. The position of the peaks within any one $12 \mathrm{~h}$ segment has been normalised to allow comparison between different traces. Normalisation was carried out by assuming a similar start time for all 4 trials, giving a common base line for the plots of phase change. The least squares regression of each line was calculated and the significance of any difference between the 2 regressions was calculated (Sokal \& Rohlf 1981).

\section{RESULTS}

As is often the case with recordings of activity for individual animals (see also Palmer \& Williams 1986a, b), some of the records showed little activity or patterns which were not clearly rhythmic. However, in the activity recordings of about a quarter (ca 50 individuals) of the crabs subjected to hypo-osmotic shock applied at the time of 'expected' low water, evidence of rhythmicity could be seen, and was usually of the pattern seen in Fig. 1. The activity is clearly bimodal on a $12.5 \mathrm{~h}$ time base, with activity peaks occurring at approximately $6 \mathrm{~h}$ intervals. It can be seen that in any one $12.5 \mathrm{~h}$ period, one of the peaks is coincident with the time of 'expected' high water on the shore and the other at $12.5 \mathrm{~h}$ intervals after introduction into $20 \%$ seawater, at the start of the experiment. Of the crabs treated in this way, which displayed clear free-running bimodal circatidal rhythmicity, 15 individuals produced activity traces which were long enough to determine the free-running periods accurately. The results of the control experiments confirm that hypo-osmotic shock is responsible for starting up the second series of peaks and that they are phased to the time of that shock. After introduction into $100 \%$ seawater $6 \mathrm{~h}$ after high water, most of the crabs ( 22 out of 30 ) continued to show a normal unimodal tidal rhythm (Fig. 2), with no evidence of a second series of peaks phased to the time of introduction as occurs in Fig. 1. The remainder showed no clear activity pattern. On the other hand, if the crabs are introduced into $20 \%$ seawater $3 \mathrm{~h}$ after high water, the induced behaviour pattern in some of the crabs (11 out of 24) is again bimodal (Fig. 3) with the second series of peaks again clearly at $12.5 \mathrm{~h}$ intervals after the start of the experiment. In this case, however (Fig. 3), the experimentally induced rhythm is about $90^{\circ}$ out of phase with the 'normal', free-running, circatidal rhythm. The remaining crabs displayed a unimodal circatidal pattern in phase with 'expected'

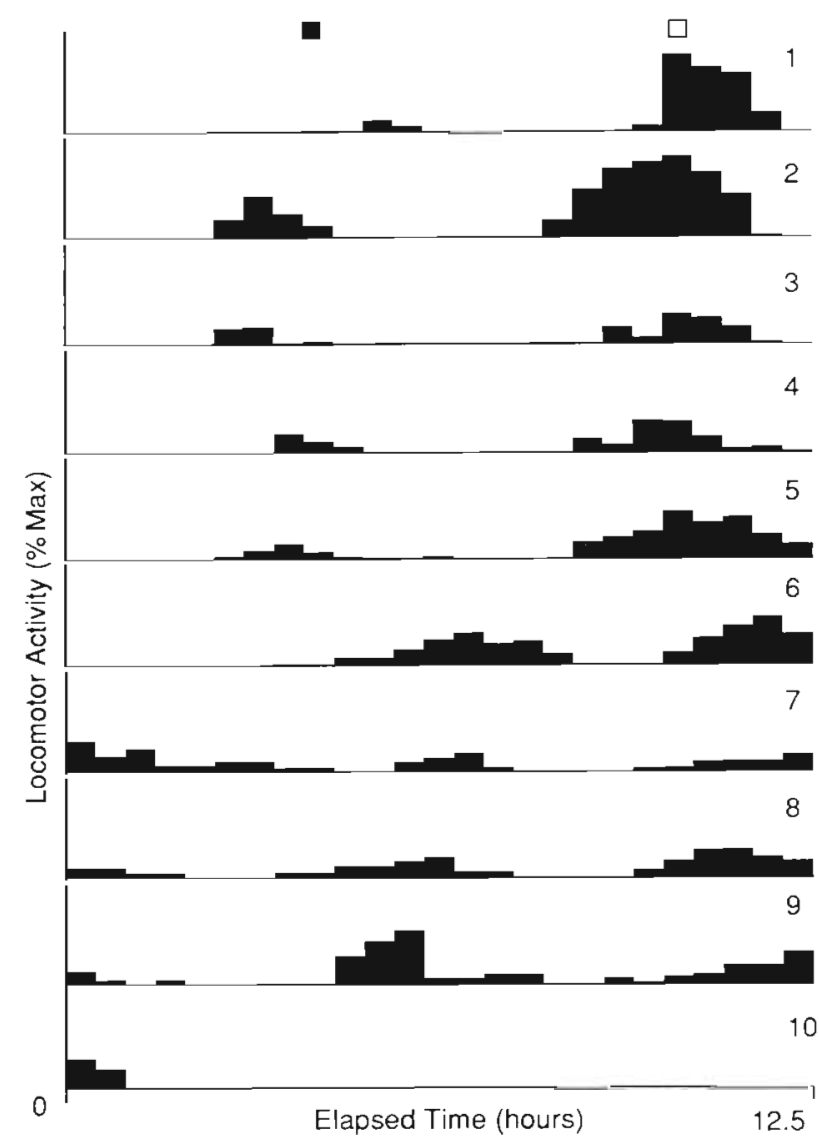

Fig. 1 Carcinus maenas. Locomotor activity pattern $(30 \mathrm{~min}$ values) for an individual freshly captured crab after introduction into low salinity water, approximately $6 \mathrm{~h}$ after expected high water. Data are plotted as 9 consecutive $12.5 \mathrm{~h}$ (circatidal) periods. ( $)$ Time of expected high water on the shore where the crabs were collected. (ㅁ) $12.5 \mathrm{~h}$ after the time of introduction into dilute seawater

high water (4 out of 24), or no clear pattern at all (9 out of 24). Clearly the phasing of the experimentally induced rhythm is determined by the timing of the initial hypo-osmotic shock irrespective of the relative time of expected high water.

Characterization of the 'split' components of the circatidal rhythm of Carcinus maenas was carried out by analysis of the activity records of the 15 individual crabs which exhibited clear and persistent bimodal circatidal rhythmicity. In most such cases, for example in Fig. 4, which shows an analysis of the data from Fig. 1, the regression lines through the timings of the 2 sets of peaks were not significantly different from each other (Table 1). However, in 4 out of the 15 crabs the results were different from those in Fig. 4. Fig. 5a to d shows the timings of the 2 sets of activity peaks for these crabs. Once again the activity patterns are apparently bimodal, but the regression plots for the 2 series of peaks show obvious differences in period (Fig. 6a to d). 


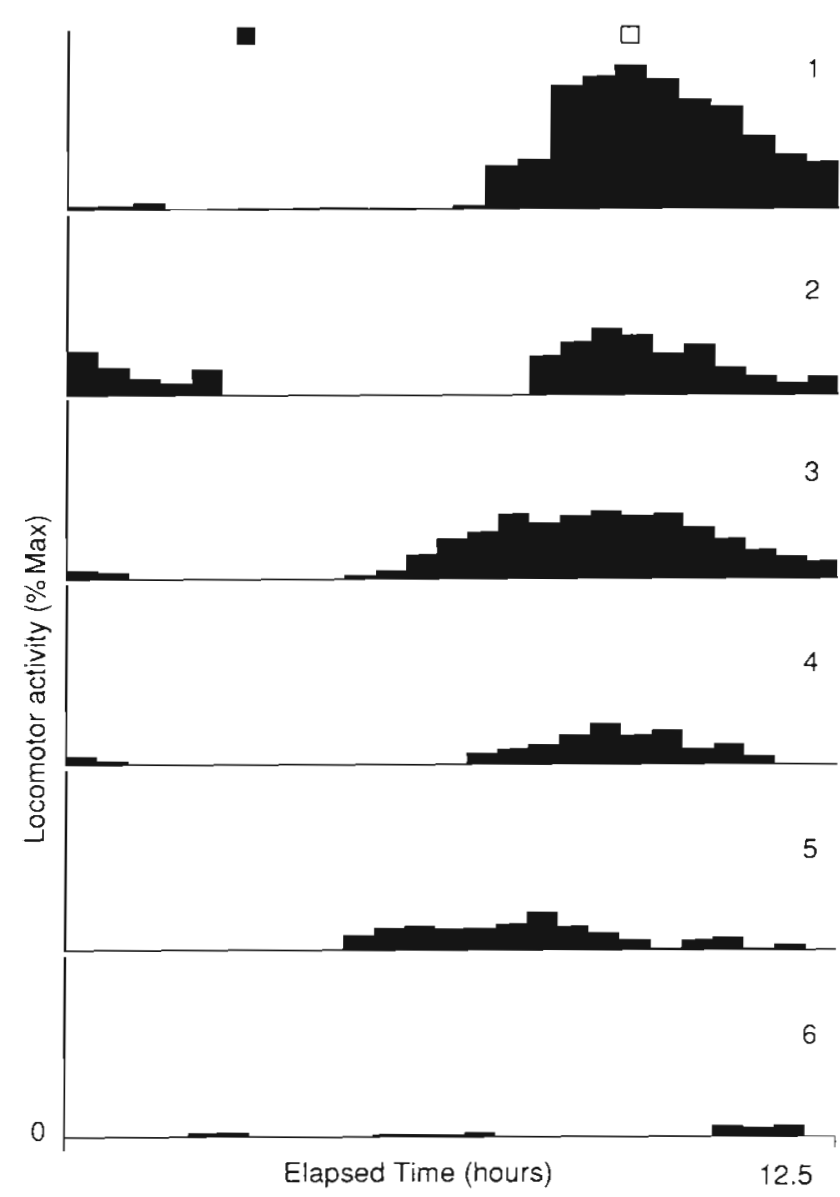

Fig. 2. Carcinus maenas. Locomotor activity pattern $(30 \mathrm{~min}$ values) for an individual freshly captured crab after introduction into normal seawater. Data are plotted as 6 consecutive $12.5 \mathrm{~h}$ (circatidal) periods. (- Time of expected high water on the shore where the crabs were collected. (ㅁ) $12.5 \mathrm{~h}$ after the time of introduction

The regressions calculated for those peaks which were initially phased to the expected tides on the shore, gave periods of between $11 \mathrm{~h} 12 \mathrm{~min}$ and $12 \mathrm{~h} 14 \mathrm{~min}$. The regressions calculated for the series of peaks initially phased to the time of the applied salinity shock gave periods of between 11 h 45 min and 12 h 17 min. The difference between the pairs of calculated regressions are all significant $(p<0.05)$. The regressions calculated for all 15 crabs during the course of the study are summarised in Table 1 . Although only 4 out of the 200 crabs tested actually displayed phaseindependent bimodal tidal behaviour, this should be considered in the context of the total of 15 individuals which displayed bimodal rhythms for any measurable period. It should be noted that this is a radical procedure, and it is not surprising that such an unnatural behaviour pattern was observed in only $7.5 \%$ of the crabs.

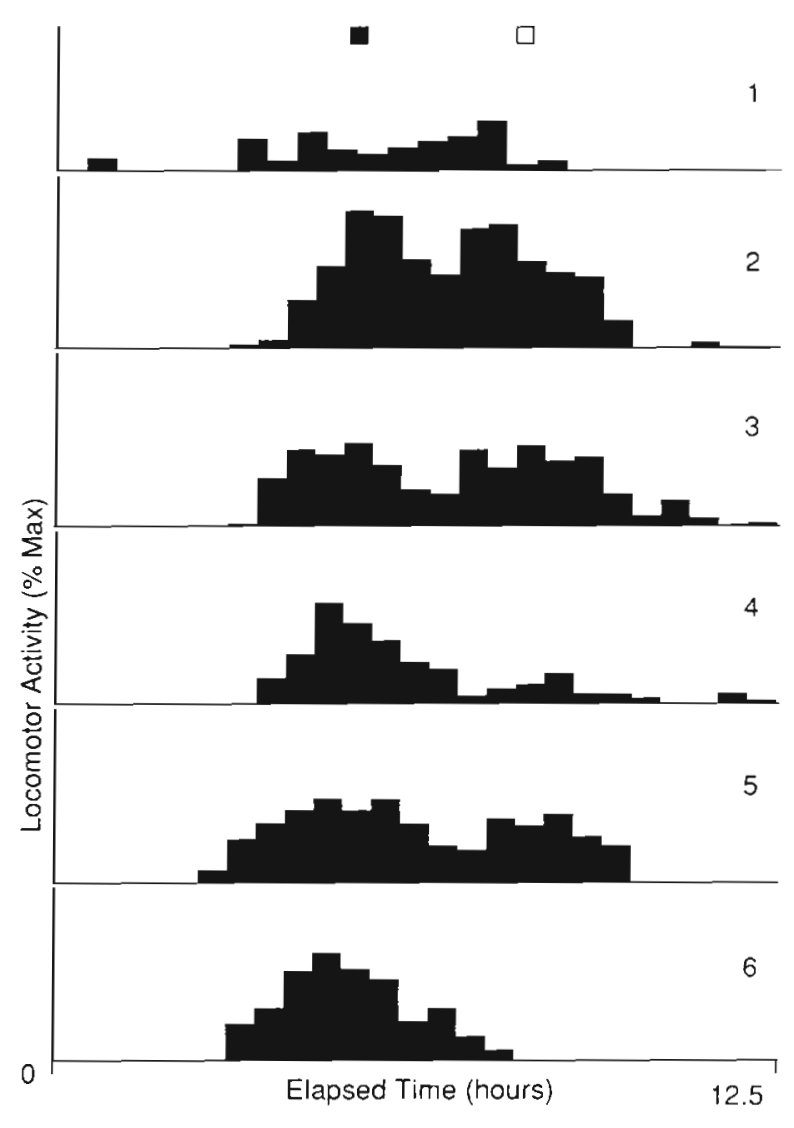

Fig. 3. Carcinus maenas. Locomotor activity pattern for an individual freshly captured crab after introduction into low salinity water, approximately $3 \mathrm{~h}$ after expected high water. Data are plotted as 6 consecutive $12.5 \mathrm{~h}$ (circatidal) periods. ( $\square$ ) Time of expected high water on the shore where the crabs were collected. (ㅁ) $12.5 \mathrm{~h}$ after the time of introduction into dilute seawater

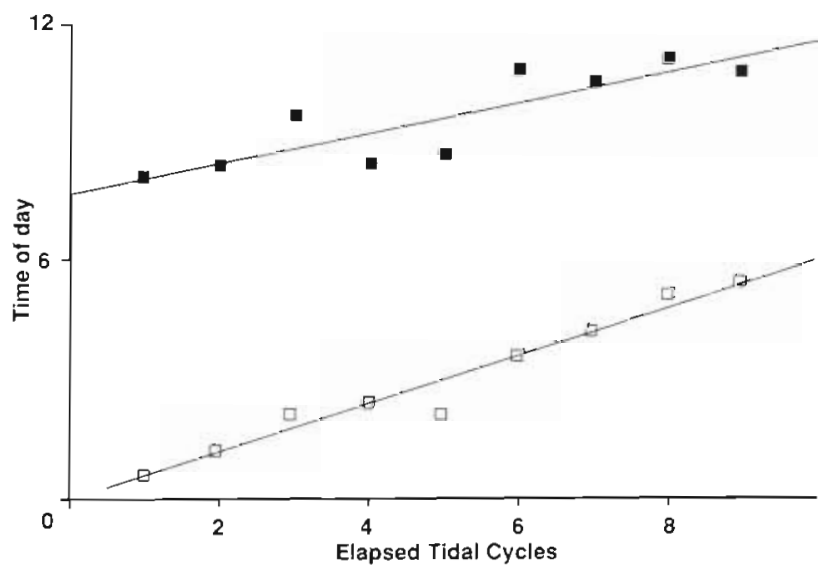

Fig. 4. Carcinus maenas. Plot of time of spontaneous locomotor activity peaks against elapsed number of tidal cycles for data presented in Fig. 1 (口) Time of peaks starting in phase with high water on the shore $(\boldsymbol{\square})$ time of the series of peaks at $12.5 \mathrm{~h}$ intervals after introduction into dilute seawater 


\section{DISCUSSION}

The results presented here clearly show that the application of hypo-osmotic shock at times other than 'expected' high water to freshly caught, rhythmically active crabs can induce an apparent bimodal circatidal rhythm, with the additional activity peaks phased to circatidal intervals after the time of first exposure to low salinity. The bimodal circatidal activity patterns obtained are very similar to the bimodal patterns which we reported previously for Carcinus maenas (Reid \& Naylor 1990). These were entrained with tidal cycles of 2 different zeitgebers imposed in $180^{\circ}$ antiphase. The present approach to starting up bimodal circatidal rhythms eliminated the necessity for the period of at least $4 \mathrm{~d}$ preliminary entrainment and was therefore quicker and simpler than our previous technique. It is difficult to assess the persistence of the induced activity peaks. C. maenas generally do not continue to display spontaneous rhythmic activity beyond a maximum of 7 to $8 \mathrm{~d}$ in the laboratory (see Houlihan \& Mathers 1985 for discussion of the response of crabs to laboratory confinement). However, during these trials, those crabs which displayed bimodal patterns of activity retained both series of peaks for the duration of the individual experiment. It is also interesting to note that in 12 cases out of 15 the period of the induced peaks was shorter than that of the field-entrained rhythm. If the basic rhythmic behavioural pattern is truly circatidal (Reid \& Naylor 1989), 2 simple models could explain this apparent bimodality, shown here and in Reid \& Naylor (1990). The first postulates the existence of a single circatidal

Table 1. Carcinus maenas. Regression estimates of the period of the natural and hypo-osmotic shock induced circatidal rhythms in 15 crabs. ns: not significant

\begin{tabular}{|c|c|c|c|}
\hline \multicolumn{2}{|c|}{ Period of rhythm } & \multirow{2}{*}{$\begin{array}{l}\text { Difference } \\
\text { in period } \\
\text { (min) }\end{array}$} & \multirow{2}{*}{$\begin{array}{l}\text { Probability } \\
\text { of significant } \\
\text { difference }\end{array}$} \\
\hline $\begin{array}{l}\text { Natural } \\
\text { circatidal }\end{array}$ & $\begin{array}{l}\text { Shock } \\
\text { induced }\end{array}$ & & \\
\hline $12 \mathrm{~h} 08 \mathrm{~min}$ & $11 \mathrm{~h} 48 \mathrm{~min}$ & 20 & ns \\
\hline $12 \mathrm{~h} 20 \mathrm{~min}$ & $12 \mathrm{~h} 28 \mathrm{~min}$ & 8 & ns \\
\hline $12 \mathrm{~h} 00 \mathrm{~min}$ & 11 h $49 \mathrm{~min}$ & 11 & ns \\
\hline $12 \mathrm{~h} 08 \mathrm{~min}$ & $11 \mathrm{~h} 58 \mathrm{~min}$ & 10 & ns \\
\hline $11 \mathrm{~h} 55 \mathrm{~min}$ & $12 \mathrm{~h} 05 \mathrm{~min}$ & 10 & ns \\
\hline $12 \mathrm{~h} 12 \mathrm{~min}$ & 11 h 46 min & 26 & $<0.05$ \\
\hline $12 \mathrm{~h} 15 \mathrm{~min}$ & 12 h $20 \mathrm{~min}$ & 5 & ns \\
\hline $12 \mathrm{~h} 23$ min & $12 \mathrm{~h} 21 \mathrm{~min}$ & 2 & ns \\
\hline $12 \mathrm{~h} 04 \mathrm{~min}$ & $11 \mathrm{~h} 45 \mathrm{~min}$ & 19 & $<0.05$ \\
\hline $12 \mathrm{~h} 14 \mathrm{~min}$ & 11 h $59 \mathrm{~min}$ & 15 & ns \\
\hline $12 \mathrm{~h} 17 \mathrm{~min}$ & 12 h $09 \mathrm{~min}$ & 8 & ns \\
\hline 11 h 59 min & $12 \mathrm{~h} 17 \mathrm{~min}$ & 18 & $<0.02$ \\
\hline $12 \mathrm{~h} 17 \mathrm{~min}$ & $12 \mathrm{~h} 11 \mathrm{~min}$ & 6 & ns \\
\hline $12 \mathrm{~h} 14 \mathrm{~min}$ & $11 \mathrm{~h} 57 \mathrm{~min}$ & 17 & $<0.05$ \\
\hline $12 \mathrm{~h} 30 \mathrm{~min}$ & $12 \mathrm{~h} 25 \mathrm{~min}$ & 5 & ns \\
\hline
\end{tabular}

oscillator of ca $12.5 \mathrm{~h}$ periodicity. This would normally cue activity only once per cycle, presumably entrained and synchronised by the various zeitgeber cycles experienced by the crab on the shore. Hypo-osmotic shock would cause a second episode of activity to be cued by this clock in phase with the timing of the hypoosmotic shock. This may be considered as analogous to placing 2 markers on the face of a clock. The second model would involve 2 (or more) separate clocks each of ca 12.5 h periodicity, but with each having a different sensitivity to the 3 main zeitgebers (Reid \& Naylor 1990). If the first of these 2 hypotheses is correct, one would expect that after hypo-osmotic shock the $2 \mathrm{com}$ ponents of the 'split' rhythm would always maintain a constant phase relationship. However, this is not the case, and therefore these results clearly favour the latter hypothesis of separate oscillators. It is important to note that even if there are 2 separate oscillators, they would often be expected to show similar free-running periods. Both components would be expected, under normal conditions, to cue for increased activity at the same phase of the tidal cycle. Only in a few cases would one expect to find that, after splitting by hypoosmotic shock, the 2 components had sufficiently different free-running periods to be detectable. The possibility of entraining an asymmetrically bimodal circatidal rhythm by the application of hypo-osmotic shock 3 h after high water (Fig. 3) also supports the hypothesis of 2 separate oscillators.

The present results therefore confirm our hypothesis (Reid \& Naylor 1990) that circatidal rhythmic behaviour in Carcinus maenas is controlled by at least 2 independent oscillators. These oscillators may themselves be composed of a large number of oscillatory components, but may be regarded functionally as discrete units. The splitting of circadian clocks into 2 separate components is well documented, particularly for the circadian rhythm of the golden hamster Mesocricetus auratus (Pittendrigh \& Daan 1976, Shibuya et al. 1980, Boulos \& Morin 1982, Earnest \& Turek 1982, Lees et al. 1983, Mrosovsky \& Hallonquist 1986) but also in other species (Lees et al. 1983). As in the present study, this splitting usually occurs only under abnormal circumstances, such as in constant light (Pittendrigh 1974, Pittendrigh \& Daan 1976), or after induced changes in hormone levels (Morin \& Cummings 1981). However, while circadian clock-splitting occurs by the slow drifting apart of activity peaks, hypo-osmotic shock results in the starting up or re-entraining of a second component of the circatidal rhythm of C. maenas in an entirely new phase. Similarly exposure of $C$. maenas to cycles of 2 different zeitgebers in antiphase also usually has the effect of suddenly reentraining the different oscillators in separate phases, rather than encouraging a slow drift apart of activity peaks (Reid \& Naylor 1990). The separate components 

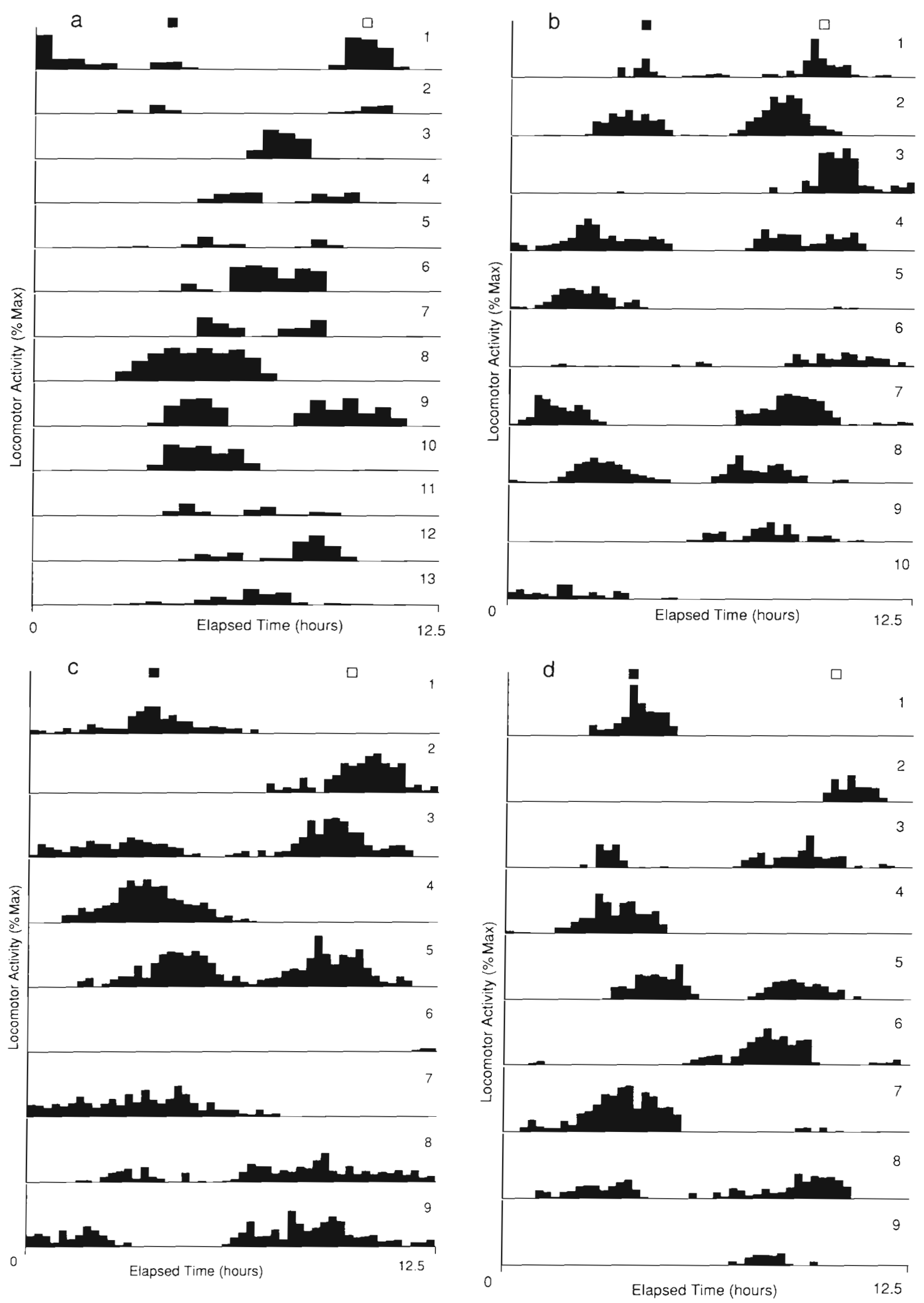
of circadian rhythmicity may, after splitting, subsequently couple in $180^{\circ}$ antiphase (Daan \& Berde 1978). In this sense coupling can be considered as the 2 components assuming a fixed and stable phase relationship. The possibility of coupling in $180^{\circ}$ antiphase of the 2 split components of circatidal rhythmicity in C. maenas may, in part, explain the relatively small proportion of the crabs studied which showed 2 series of peaks with significantly different free-running periods, both in the present work and in Reid \& Naylor (1990). As the crabs were first exposed to hypo-osmotic shock approximately $6 \mathrm{~h}$ after high water, the resulting behaviour pattern would be symmetrically bimodal, with the 2 oscillator components already in approximate $180^{\circ}$ antiphase.

In Reid \& Naylor (1990) we proposed that these oscillators may be differentiated by their sensitivities to the 3 main zeitgebers of circatidal rhythmicity in this species: salinity, temperature and hydrostatic pressure. One possibility would be for each oscillator to respond in a hierarchical fashion to the 3 zeitgebers. For instance, one oscillator may be most sensitive to pressure changes, less so to salinity and even less so to temperature. The other oscillator may be most sensitive to temperature change and less so to others. A second possibility is that there are more than 2 separate oscillators, each of which could be coupled to, and synchronised by, a different tidally cyclic environmental variable, via a specific transduction mechanism. It should be emphasised however that, at present, there is only evidence for 2 separate oscillators. Under normal circumstances, on the shore, the different oscillators, with their different sensitivities to the various tidal variables, would be expected to entrain with a common phase. Typically the 3 main tidal zietgebers would normally retain a fixed phase relationship on the shore, high water being characterized by high salinity, high pressure and low temperature (at least in summer). There may also be some mutual entrainment between the different oscillators which might keep them in synchrony. Mutual entrainment would be where one oscil- lator entrains another to the same phase. Mutual entrainment has been suggested elsewhere for populations of individual oscillators (Nanjundiah 1986).

The identification of 2 or more circatidal oscillators which can be distinguished by different responses to potential zeitgebers, rather than different functions, could be of considerable interest. Most of the evidence for multiple circadian oscillators is for functionally distinct circadian clocks, for example in the range of behaviours displayed by the tsetse fly Glossina morsitans (Brady 1981), and in man (Aschoff 1969, Wever 1979 ) or in plant growth rhythms (Ball \& Newcombe 1961). The clock splitting demonstrated experimentally in hamsters and other small mammals produces 2 separate components, both of which control locomotor activity, but these are usually identified either as dawn and dusk activity rhythms (Pittendrigh \& Daan 1976, Daan \& Berde 1978) or as rhythms controlling activity onset and offset (Lees et al. 1983, Pohl 1985) and so may still be considered as functionally distinct. Present findings with Carcinus maenas suggest that the normally cophasic (i.e. in the same phase) circatidal oscil-

Fig. 5. Carcinus maenas. Locomotor activity pattern for 4 individual freshly captured crabs (a to d) after introduction into low salinity water, approximately $6 \mathrm{~h}$ after expected high water. The times of the peaks have been normalised for comparison. Data are plotted as $13,10,9$ and 9 consecutive $12.5 \mathrm{~h}$ (circatidal) periods, respectively. ( $\mathbf{}$ ) Time of expected high water on the shore where the crabs were collected. ( $\square$ ) $12.5 \mathrm{~h}$ after the time of introduction into dilute seawater 
lators control increased locomotor activity at times of expected high water. The oscillators can best be differentiated by zeitgeber influence, rather than function. This differentiation might be expected in a rhythmic system with the multiplicity of possible entraining influences of C. maenas. It may be useful to re-examine the circadian clocks of animals which entrain to more than 1 variable e.g. light: dark cycles and temperature cycles or social interaction, and to determine if circadian rhythms may also have zeitgeber-specific oscillators.

\section{LITERATURE CITED}

Aschoff, J. (1969). Desynchronization and resynchronisation of human circadian rhythms. Aerosp. Med. 40: 844-849

Ball, N. G., Newcombe, G. B. (1961). The relationship between the growth of the primary leaf and coleoptile in seedlings of Avena and Triticum. J. exp. Bot. 12: 114-128

Bolt, S. R. L., Naylor, E. (1986). Entrainability by salinity cycles of rhythmic locomotor activity in normal and eyestalk ablated Carcinus maenas (L.). Mar. Behav. Physiol. 12: $257-267$

Bolt, S. R. L., Reid, D. G., Naylor, E. (1989). Effects of combined temperature and salinity on the entrainment of endogenous rhythms in the shore crab Carcinus maenas. Mar. Behav. Physiol. 14: 245-254

Boulos, Z., Morin, L. P. (1982). Entrainment of split circadian rhythms in hamsters. Soc. Neurosci. Abstr. 8: 545

Brady, J. (1981). Behaviourial rhythms in invertebrates. In: Aschoff, J. (ed.) Handbook of behavioural neurobiology, Vol. 4, Biological rhythms. Plenum, New York, p. 125-144

Daan, S., Berde, C. (1978). Two coupled oscillators: simulations of the circadian pacemaker in mammalian activity rhythms. J theor. Biol. 70: 297-313

Earnest, D. J., Turek, F. W. (1982). Splitting of the circadian rhythm of activity in hamsters: Effects of exposure to constant darkness and subsequent re-exposure to constant light. J. comp. Physiol. 145: 405-411

Harris, G. J., Morgan, E. (1984). Entrainment of the circatidal rhythm of the estuarine amphipod Corophium volutator (Pallas) to non-tidal cycles of inundation and exposure in the laboratory. J. exp mar. Biol. Ecol. 80: 235-245

Houlihan, D. F., Mathers, E. (1985). Effects of captivity and exercise on the energetics of locomotion and muscle in Carcinus maenas (L.). J. exp. mar. Biol. Ecol. 92: 125-142

Lees, J. G., Hallonquist, J. D., Mrosovsky, N. (1983). Differential effects of dark pulses on the two components of split

This article was submitted to the editor circadian activity rhythm in golden hamsters. J. comp. Physiol. 153: 123-132

Morin, L. P. Cummings, L. A. (1981). Effect of surgical or photoperiodic castration, testosterone replacement or pinealectomy on male hamster running rhythmicity. Physiol Behav. 24: 825-838

Mrosovsky, N., Hallonquist, J. D. (1986). Colliding of activity onset and offset: evidence for multiple circadian oscillators. J. comp. Physiol. (Sec. A) 159: 187-190

Nanjundiah, V. (1986). How rapidly do uncoupled oscillators desynchronize. J. theor. Biol. 121: 375-379

Naylor, E., Williams, B. G. (1984). Environmental entrainment of tidally rhythmic behaviour in marine animals. Zool. J. Linn. Soc. 80: 201-208

Palmer, J. D., Williams, B. G. (1986a). Comparative studies of tidal rhythms. II. The dual clock control of the locomotor rhythms of two decapod crustaceans. Mar. Behav. Physiol. 12: $269-278$

Palmer, J. D., Williams, B. G. (1986b). Comparative studies of tidal rhythms. I. The characterization of the activity rhythm of the Pliant-pendulum crab, Helice crassa. Mar. Behav. Physiol. 12: 269-278

Pittendrigh, C. S. (1974). Circadian oscillators in cells and the circadian organization of multicellular systems. In: Schmitt, F. O., Worden, F. G. (eds.) The neurosciences: third study program. Massachusetts Institute of Technology, Cambridge, p. $437-458$

Pittendrigh, C. S., Daan, S. (1976). A functional analysis of circadian pacemakers in nocturnal rodents. V. Pacemaker structure: a clock for all seasons. J. comp. Physiol. 106: $333-355$

Pohl, H. (1985). The circadian systern of the Turkish hamster Mesocritus brandti: responses to light. Comp. Biochem. Physiol 81A: 613-618

Reid, D. G., Naylor, E. (1989). Are there separate circatidal and circadian clocks in the shore crab Carcinus maenas? Mar. Ecol. Prog. Ser. 52:1-6

Reid, D. G., Naylor, E. (1990). Entrainment of bimodal circatidal rhythms in the shore crab Carcinus maenas. J. biol. Rhythms. 5: 333-347

Turek, F. W., Earnest, D. J., Swann, J. (1982). Splitting of the circadian rhythm of activity in hamsters. In: Aschoff, J., Daan, S., Groos, G. (eds). Vertebrate circadian systems. Springer, Berlin, p. 203-214

Shibuya, C. A., Melynk, R. B., Mrosovsky, N. (1980). Simultaneous splitting of drinking and locomotor activity rhythms in the golden hamster. Naturwissenschaften 67: 45-47

Sokal, R. S., Rohlf, F. J. (1981). Biometry, 2nd edn. W. H. Freeman \& Co, San Francisco

Wever, R. (1979). The circadian system of man. Springer, Berlin

Manuscript first received: June 24, 1992

Revised version accepted: August 2, 1993 